\title{
A expansão econômica e geopolítica da China no século XXI: diferentes dimensões de um mesmo processo
}

\author{
Javier Vadell (Org.) \\ Editora PUC Minas, 2018, 287 páginas
}

\author{
Aldana Arias Britos
}

¿Cuál es el marco teórico que da vida a las relaciones internacionales en China?, ¿Qué influencia ha tenido el gigante asiático en el desarrollo económico del Sur Global?, ¿Son China y Estados Unidos, en realidad, tan distintos?

El libro que presenta la Editora PUC Minas es una compacta pero exhaustiva recolección de ponencias realizadas en el III Seminario sobre Potencias Medias, en agosto del 2016, organizado por la Pontificia Universidad Católica de Minas Gerais y por el Instituto de estudios sobre Asia (IEA) de la Universidad Federal de Pernambuco.

El ascenso político y económico de China en el orden mundial contemporáneo es, sin duda para todos los analistas de este libro, el acontecimiento más importante de las relaciones internacionales de los últimos 15 años. Es también, una marca indeleble en el rumbo del siglo XXI.

Siguiendo un riguroso criterio, el primer capítulo sumerge al lector en una comprensión teórica de las relaciones internacionales chinas. Marcos Costa Lima retoma el concepto de «Tianxia»; surgido en la china antigua; para indagar como es que en la perspectiva asiática las relaciones internacionales, la legitimidad del poder y los cambios que se producen en el escenario mundial son entendidos de manera radicalmente diferente a la occidental, primordialmente, a las teorías desarrolladas en
Estados Unidos. A medida que el capitulo avanza, el autor rastrea a los principales teóricos de las relaciones internacionales chinas para dar cuenta de los interrogantes que impulsaron el desarrollo de esta disciplina e intentar dilucidar las respuestas más pertinentes.

El segundo capítulo del libro está escrito por Li Xing y Timothy Shaw, en donde ambos analizan el nexo que existe entre el orden mundial, liderado por los Estados Unidos, y el ascenso de China en este orden, considerando los conflictos y tensiones que se desencadenan entre estos dos actores. Los autores se sirven de una brillante anagogía entre dos proverbios chinos «dormir en la misma cama con sueños distintos» $\mathrm{y}$ «montar el tigre»- junto con el conocido refrán de «el sueño americano» para entender como estas dos potencias han interactuado a lo largo del siglo XX. Es así que los autores revelan su principal hipótesis: sustentándose en la teoría de la transición de poder desarrollada por Organski y Kugler en 1980, las posibilidad de un enfrentamiento armado entre Estados Unidos y China aumentaran en contextos en donde una potencia emergente amenace con remplazar al hegemón dentro del sistema internacional. Las apreciaciones de Xing y Shaw demuestran el taciturno carácter de las relaciones entre ambos países: un vínculo que se ha tornado necesario para ambos circunscripto en una puja de poder continua. 
Los tres capítulos que se desarrollan a continuación versan sobre la influencia económica que ha tenido el gigante asiático en diferentes regiones del mundo. La inversión externa directa que ha generado este país es un factor clava para entender su influencia regional y mundial, así como para esclarecer sus vínculos con la Unión Europea, que a pesar de presentar fluctuaciones, han sabido volverse rutinarias. Yuan Ma y Henk Overbeek estudian los diferentes factores de atracción que la UE presenta para atraer un considerable porcentaje de las inversiones externas directas de China, y presentan sus hipótesis sobre porque esta organización presenta un ambiente de inversión relativamente amigable para inversores chinos luego de la crisis economía europea.

Seguidamente, Giuseppe Lo Brutto descifra los cambios económicos y políticos de América Latina, para posteriormente entender que futuro poseen las relaciones entre este continente y el país chino como consecuencia directa de las dinámicas de Cooperación SurSur. Esta nueva estrategia de comercialización, no solo engloba las estrategias para el cambio rotundo en las regiones que involucra sino que también es considerada una útil herramienta para transformar el orden mundial impulsando la independencia económica y política de los países que las lleven a cabo. China se encuentra actualmente entre los socios más activos de América Latina, mediante la consolidación de acuerdos multilaterales y bilaterales que le aseguran una marcada presencia geopolítica y económica en la región. Enfrentados a un escenario internacional multipolar, el posicionamiento geopolítico y geoeconómico es un punto clave en las relaciones entre China y América Latina.
Estas conclusiones encuentran un reflejo en el capitulo siguiente, en donde el foco de atención es puesto en el rol que ha tomado China respecto del continente africano: su renacimiento. Resaltando las particularidades del caso, Rafael Domínguez detalla la presencia china en terreno económico africano, las doctrinas de colaboración económica dirigidas por China y los diferentes momentos de tensión y amistad diplomáticos que han acontecido entre ambos países. En comparación con otras potencias como Estados Unidos y Japón, China represento al continente africano una alternativa saludable para comenzar un desarrollo económico libre de condicionalidades políticas, cimentado en una historia común de dominación imperial por parte de las potencias occidentales.

Mariana Burger inicia un nuevo capítulo respecto al posicionamiento de China en la sociedad internacional retomando su posicionamiento frente a las problemáticas territoriales que se originaron en el mar del sur de China, en donde el reclamo de los diferentes países de la región sobre aéreas que se superponen determino un antecedente fundamental para comprender las relaciones entre los países en la actualidad. Una de las aristas de esta temática analizadas por la autora es como el -nuevogigante asiático fiara sus objetivos e intereses geopolíticos y territoriales en función de su acelerado crecimiento económico. Una política exterior basada en la idea de que el advenimiento chino como gran potencia no implica desventajas o perjuicios a otras naciones, sustentándose en principios confucianos, le ha dado a China la posibilidad de embarcarse en políticas de «community of practice» con el resto de sus vecinos. 
En el capítulo siete, Javier Vadell y Pedro Neves cotejan la evolución de las relaciones comerciales entre la Republica Popular China y Brasil en el siglo XXI. Con el propósito de analizar el creciente vinculo político, económico y regional que el país oriental ha establecido con Brasil, seleccionan dos aspectos a partir de los cuales desarrolla su trabajo: en primera instancia, la importancia de ese vinculo para el desarrollo de la región de América Latina, dejando para la segunda parte del su composición una comprensión minuciosa de la interacción chino- brasilera como un resultado de la política «going global» desarrollada por China. Considerando que las relaciones entre China y América Latina responden a una nueva etapa de inserción en el capitalismo global, la breve investigación de estos internacionalistas apunta a develar las nuevas relaciones de (inter)dependencia asimétrica entre ambos países.

Bien encaminados hacia el final del libro, las últimas dos ponencias elegidas para completarlo versan sobre aspectos de la economía internacional y la independencia monetaria que Chi- na ha programado desde la última década; así como su desenvolvimiento regional desde una óptica cualitativa para medir su mejoría interna. Las políticas de internacionalización de la moneda china constituyen la piedra angular para lograr una mayor independencia del dólar en el plano de la economía mundial, sin por eso permitir que la economía nacional quede indefensa a las fluctuaciones e inestabilidades que presenta la economía internacional. Comprender estas políticas, permitirán a cualquier analista comprender las actuales posiciones del país que posee la segunda economía más grande del mundo.

En suma, este libro proporciona ángulos e interpretaciones innovadoras, actuales y precisas a la hora de asomarse al entendimiento de los desafíos que China plantea al mundo y aquellos a los que ella misma como nación ha tenido que sobrellevar para recuperar su posición de potencia a nivel regional y mundial. Javier Vadell presenta un provechoso trabajo para todos aquellos interesados en la futura configuración del orden internacional. 